\title{
Structural Optimization for Column of Gantry Machine Tool Using Response Surface Method
}

\author{
M.J. Twu, S.B. Yu \\ Department of Mechatronic Engineering \\ National Taiwan Normal University \\ Taipei, R.O.C.
}

\begin{abstract}
As the first part of an ongoing integrated project for developing a desktop gantry grinding machine tool, the structural optimization of column part is taken as the focus of the study. The thickness, height, and width of column are the design variables. The objective of optimization is to minimize volume while keeping the deformation of spindle tip smaller than the desired maximum value and the 2 nd natural frequency below the given limit. Based on results of static and dynamic analyses obtained from finite element method, the response surface method with factorial design was utilized to create the metamodel for optimization. Two kinds of response surface model with two kinds of factorial design were used for comparison. The gradient search method was applied to the response surface model for optimization. The optimal structure of machine tool made the volume and the second natural frequency both decreasing $13 \%$ while the y-displacement of spindle tip were confined to required range. The result shows the successful application of response surface method with carefully chosen factorial design on structural optimization problem.
\end{abstract}

Keywords-structural optimization; gantry machine tool; response surface method; finite element analysis

\section{INTRODUCTION}

Machining processes is the fundamental manufacturing techniques and expected to remain so for the next few decades [1]. To achieve high precision machining the static and dynamic properties of machine tool are the major factors. Those properties are greatly influenced by the machine configuration which should be evaluated very early in the design phase. The structural design of mechanical components has great impact on the machining performance [2].

A gantry type high precision grinding machine tool is currently under our development. Because it is a desktop machine, the geometric dimensions are limited within given range. Due to the constrained sizes of other available parts, the column part is the focus of structural design. The light weight design with good dynamic properties is our first concern. The optimal design problem is to find minimum weight or volume of machine tool with suitable stiffness and natural frequency. The finite element method (FEM) is popular and widely used for machine tools simulation $[3,4]$; hence this study used FEM to get static and dynamic response of machine tool for optimization procedure.

Metamodel or referred as surrogate model, is used in many disciplines [5, 6]. Since it is not possible or efficient to analyze all of the combinations of variables, especially for the case of optimization, metamodel is a cheaper alternative. The response surface method (RSM) is chosen as metamodel for this study due to its successful applications in engineering design and optimization $[5,7,8,9]$.

The remainder of the paper is organized as follows. The structural optimization problem for the proposed gantry grinding machine tool is described in section 2. Section 3 discusses the basic theory and methodology including RSM, factorial design for optimization. The finite element analysis and optimization procedure are described in section 4 . The optimal results are discussed in section 5. Conclusions are drawn in section 6 .

\section{PROBLEM DESCRIPTION}

The goal of this study is to develop an optimal structure for the proposed grinding machine as shown in fig. 1 (a). The chosen design variables are the dimension of column: length $\mathrm{xL}(\mathrm{x})$, height $\mathrm{yH}(\mathrm{y})$ and width $\mathrm{zW}(\mathrm{z})$, as shown in fig. 1(b).

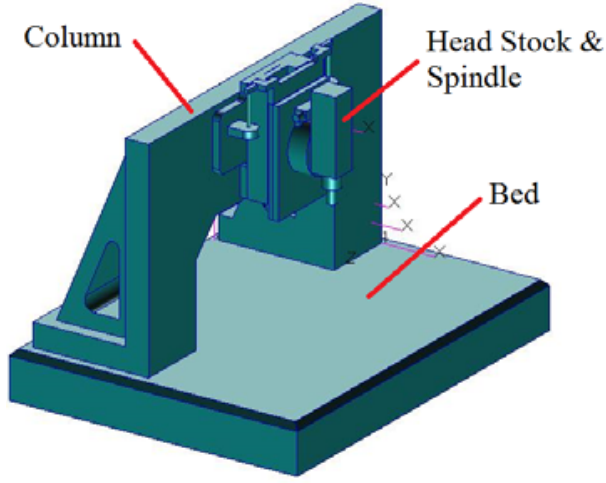

(A) SIMPLIFIED ANALYSIS MODEL

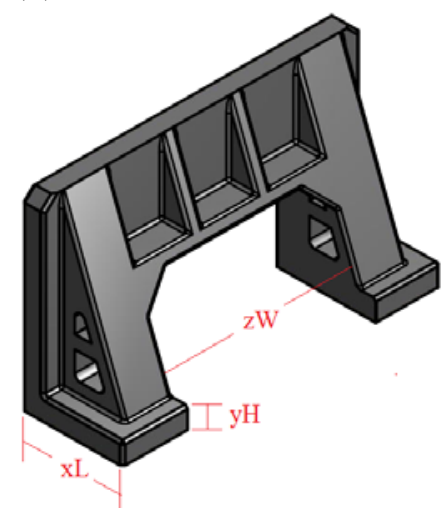

(B) DESIGN VARIABLES

FIGURE I. HIGH-SPEED DUAL-SPINDLE GRINDING MACHINE 
The objective of optimization is the minimal volume of column Vc. The constraints are y-deformation of tip of spindle, maximum von Mises stress, and the natural frequency. The optimization problem is written as following:

Objective: $\mathrm{V}_{\mathrm{c}}$

$$
\text { Constrains: } y_{\text {tip }} \leq y_{\max }, \sigma \leq \sigma_{\text {max }}, \quad f_{n} \leq f_{\max },
$$

where $\sigma_{\max }$ is the maximal yielding stress of material, $y_{\max }$ the maximum displacement, $f_{n}$ the natural frequency of nth mode, and $f_{\max }$ the maximal value of frequency. The suitable values of $y_{\max }, \mathrm{n}$, and $f_{\max }$ were decided in accordance with the static and dynamic behaviour requirements of design based on the results of preliminary study which is described in section 4

\section{Methodology}

\section{A. Response Surface Method}

In general, RSM denotes a collection of statistical and mathematical techniques used in constructing approximation of functional relationship between controlled variables and corresponding response of interest [10]. RSM is frequently used as one method for design of experiments (DOE). The basic theory of RSM is described as follows [10, 11]. The unknown relationship between interested response $\mathrm{y}$ and $\mathrm{k}$ factors (or design variables), denoted by $x_{1}, x_{2}, \ldots, x_{k}$, can be approximated by a frequently used second order model as follows:

$$
y=\beta_{0}+\sum_{i=1}^{k} \beta_{i} x_{i}+\sum_{i=1}^{k} \beta_{i i} x_{i}^{2}+\sum_{i=1}^{k} \sum_{j=1}^{k} \beta_{i j} x_{i} x_{j}+\varepsilon .
$$

In the above equation $\varepsilon$ is the comprehensive error, $\beta_{i}$ and $\beta_{i}$ equations can be written in the general form in vector and matrix notation as

$$
\mathbf{y}=\mathbf{X}^{\mathrm{T}} \mathbf{b}+\mathbf{e} .
$$

The row of matrix $\mathrm{X}$ is vector $\mathrm{xi}$, while the component of vector e consists of the corresponding error. The least square method is used to obtain the vector of regression coefficient vector b.

\section{B. Factorial Design}

Factorial design means to investigate all possible combinations of the levels of the factors (design variables) in each experiment or analysis of design [11]. We only consider the following two methods in this study for comparison:

1. Full-factorial design: All combinations of all factors of all levels are evaluated. It gives extensive information, but costs.

2. Box-Behnken Design: It is suitable for that situation without values at corners [12]. It is very efficient for 3-levels design for second order response surfaces. The levels of factor are represented by $-1,0,1$. Table 1 gives Three-variable BoxBehnken design [11].

TABLEI. Three-VARIABLE BoX-BeHNKen Design

\begin{tabular}{|c|c|c|c|}
\hline Experiment \# & $\mathbf{x}_{\mathbf{1}}$ & $\mathbf{x}_{\mathbf{2}}$ & $\mathbf{x}_{\mathbf{3}}$ \\
\hline 1 & -1 & -1 & 0 \\
\hline 2 & -1 & 1 & 0 \\
\hline 3 & 1 & -1 & 0 \\
\hline 4 & 1 & 1 & 0 \\
\hline 5 & -1 & 0 & -1 \\
\hline 6 & -1 & 0 & 1 \\
\hline 7 & 1 & 0 & -1 \\
\hline 8 & 1 & 0 & 1 \\
\hline 9 & 0 & -1 & -1 \\
\hline 10 & 0 & -1 & 1 \\
\hline 11 & 0 & 1 & -1 \\
\hline 12 & 0 & 1 & 1 \\
\hline 13 & 0 & 0 & 0 \\
\hline 14 & 0 & 0 & 0 \\
\hline 15 & 0 & 0 & 0 \\
\hline
\end{tabular}

We took three levels and only considered 3k factorial design, where factor $\mathrm{k}=3$ since there are three design variables. Three-variable Box-Behnken design was chosen for building response surface model. For the purpose of comparison, the full-factorial design also was used.

\section{ANALYSES AND OPTIMIZATION}

\section{A. Design And Analysis Procedure}

Three software packages are used in this study. The structural static and dynamic analyses are performed by finite element analysis package MSC.Nastran with its pre-processor MSC.Patran. The mathematical software package Mathematica is used to set up the design variables for MSC.Patran calling MSC.Nastran to do the analysis for each design. The values of design variables of initial design are: $x L=200 \mathrm{~mm}, y H=40 \mathrm{~mm}, z W=355 \mathrm{~mm}$. The boundary condition is the fixed perimeter of the bed. The loading is uniform pressure (equivalent to 10 Newton force) applied on the tip of spindle. The material of bed and column is ASTM grade 60 Grey cast iron, while the material of head stock (and spindle) is Aluminum 6061-T6Al 6061.

Three kinds of analysis were performed for each design: static analysis, modal analysis, and frequency response analysis. For full factorial design total 81 analyses were used, while only 39 analyses among them were used for BoxBehnken design. The sensitivity study was performed to understand the sensitivity of response with respect to the design variables.

After obtaining and scrutinizing the results from finite element analyses of full factorial design, we get the following summary:

(1). The maximum value of ytip is lower than $3.5 \mathrm{um}$, thus ymax $=3.5$.

(2). The maximum value of von Mises stress is very small compared to the yielding strength. It is an inactive constraint, hence not considered. 
(3). The variation of first natural frequency is less than $0.5 \%$ for all designs, since it comes from the nodding motion of the head stock and the dimension change of column does not give much impact. The only way to change the first natural frequency is to modify the size of head stock while it is not considered in this study due to the limitation of available size of its components.

(4). The constraint for natural frequency will be put on the second one, because it is the second important. Then fmax takes the value of initial design $425 \mathrm{~Hz}$.

The above information gives some useful guidelines to set up succeeding optimization problem.

\section{B. Response Surface Model}

We take $3_{\mathrm{k}}$ factorial design in the study with design variables as shown in table 2 .

TABLEII.

FACTORS AND LEVELS OF DESIGN

\begin{tabular}{|l|c|c|c|c|}
\hline & Normalized value & $\mathbf{x L}(\mathbf{m m})$ & $\mathbf{y H ~ ( m m )}$ & $\mathbf{z W}(\mathbf{m m})$ \\
\hline Level 1 & -1 & 175 & 35 & 320 \\
\hline Level 2 & 0 & 200 & 40 & 355 \\
\hline Level 3 & +1 & 225 & 55 & 390 \\
\hline
\end{tabular}

Two kinds of response surface model are used as follows:

$$
S_{1}=\beta_{0}+\beta_{1} x+\beta_{2} y+\beta_{3} z+\beta_{12} x y+\beta_{13} x z+\beta_{23} y z+\beta_{11} x^{2}+\beta_{22} y^{2}+\beta_{33} z^{2},
$$

$$
\begin{aligned}
S_{2}= & \beta_{0}+\beta_{1} x+\beta_{2} y+\beta_{3} z+\beta_{12} x y+\beta_{13} x z+\beta_{23} y z+\beta_{11} x^{2}+\beta_{22} y^{2}+\beta_{33} z^{2}+. \\
& \beta_{123} x y z+\beta_{122} x y^{2}+\beta_{133} x z^{2}+\beta_{112} x^{2} y+\beta_{113} x^{2} z+\beta_{233} y z^{2}+\beta_{223} y^{2} z
\end{aligned}
$$

Each equation uses two kinds of factorial design: full factorial design and Box-Behnken design. For each design cases, three kinds of finite element analysis were performed. To validate the response surface method three test cases were performed to check the percentage error of discrepancy between analysis results and predicted values of response surface model.

\section{Formulations of Optimization}

After the preliminary design study, we found that the von Mises stresses in structure are far below the yielding stress of material due to very small applied force. Hence the constraint of stress is inactive and not used in optimization process. The aforementioned optimization formulation for this study is

$$
\begin{array}{ll}
\min . & V_{c}(\mathbf{x}), \mathbf{x} \in R^{3} \\
\text { s.t. } & \mathbf{g}(\mathbf{x}) \leq 0, \mathbf{g} \in R^{2} .
\end{array}
$$

The design variable vector is $\mathbf{x}^{T}=[\mathrm{xL} y H z W]$ shown in fig. 1(b). The objective $V_{c}$ is the volume of column of machine tool, while the constraints are the maximum value of y-displacement of spindle tip and the 2nd natural frequency as follows:

$$
\mathbf{g}(\mathbf{x})=\left\{\begin{array}{c}
y_{\text {tip }}(\mathbf{x})-y_{\max } \\
f_{2}(\mathbf{x})-f_{\max }
\end{array}\right\} \text {. }
$$

Depending on the response surface model used, the objective function $V_{c}$ and constraint functions $\left(y_{\text {tip }}\right.$, and $\left.f_{2}\right)$ take the expression of eqn. (3) or eqn. (4). Because those are nonlinear polynomial functions, the gradient search method can be easily applied for solving this optimization problem [13, 14].

\section{RESULTS AND DISCUSSION}

\section{A. Response Surfaces}

The regression coefficients of response surface model were obtained using least square method presented in section 2 . The response surface ${ }^{S_{1}}$ can be visualized in surface contour plot illustrated in fig. 2. In Those plots there are ten contour surfaces. Each contour surface represents one value of objective. The model of full factorial design and Box-Behnken design are put together for comparison. It shows that there is not too much difference between them.

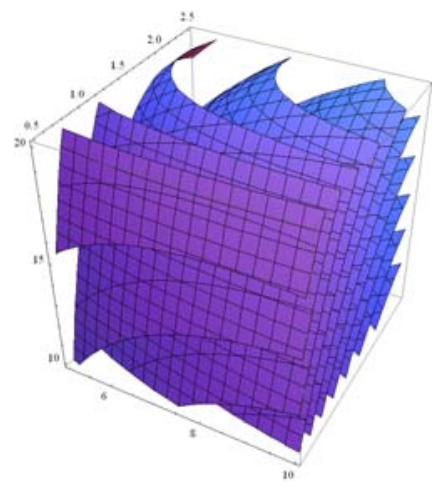

(a) Full factorial design

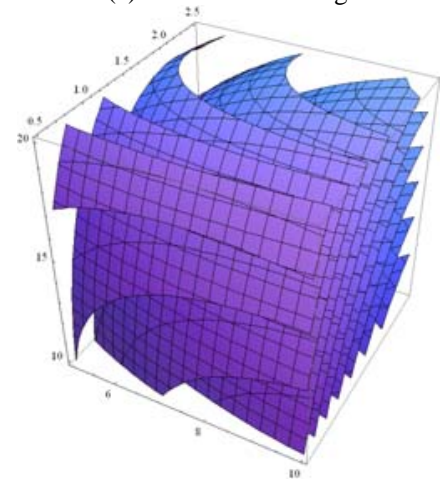

(b) Box-Behnken design

FIGURE II. RESPONSE SURFACES OF OBJECTIVE USING SURFACE MODEL S1

Three test cases were run to validate these two response models, s1 and s2, with full factorial design and Box-Behnken design. Each test compares the results predicted by the response models with analysis results from finite element package. The percentage errors of all test cases are shown in fig. 3. The comparison shows that the response model can match the finite element model very well, since the discrepancy errors are all below $1.5 \%$. The response surface models $S_{1}$ and $S_{2}$ give almost indistinguishable predictions. 


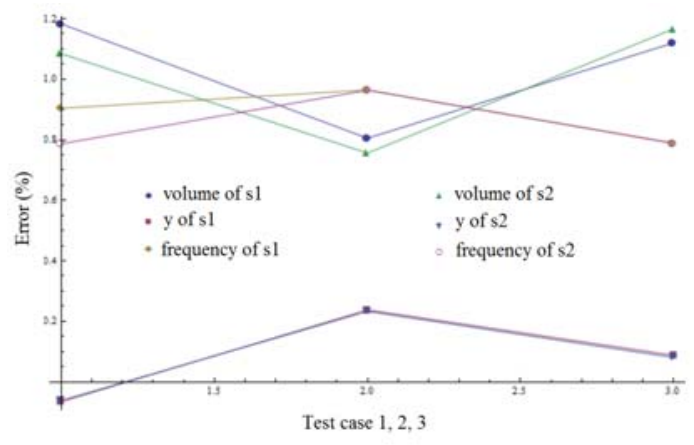

FIGURE III. ERROR (\%) OF TEST CASES USING S1 AND S2 FOR FULL FACTORIAL DESIGN

\section{B. Optimal Results}

With the response surface model the optimal design were obtained by using the aforementioned method. The values of design variables of optimal design are: $\mathrm{xL}=175 \mathrm{~mm}, \mathrm{yH}=25$ $\mathrm{mm}, \mathrm{zW}=375 \mathrm{~mm}$. The optimal design gives $13.3 \%$ reduction in volume, $2.43 \%$ increment in y-displacement, and $14.8 \%$ reduction in 2nd natural frequency. Comparison between original design and optimal design are given in table 3.

TABLEIII. COMPARISON BETWEEN ORIGINAL DESIGN AND OPTIMAL DESIGN

\begin{tabular}{|c|c|}
\hline Original design variables $(\mathrm{xL}, \mathrm{yH}, \mathrm{zW})(\mathrm{mm})$ & $(200,40,355)$ \\
\hline Optimal design variables $(\mathrm{xL}, \mathrm{yH}, \mathrm{zW})(\mathrm{mm})$ & $(175,25,375)$ \\
\hline Change of volume & $-13.3 \%$ \\
\hline Change of y-displacement & $+2.43 \%$ \\
\hline Change of $2^{\text {nd }}$ natural frequency & $-14.8 \%$ \\
\hline
\end{tabular}

\section{CONCLUSIONS}

The structural optimization for column part of gantry grinding machine tool is conducted successfully in this study. The objective of optimization is to minimize the volume of machine tool while subjected to the constraints of the ydisplacement of spindle tip and the 2nd natural frequency. The design variables are dimensions of column part of machine tool. Both static and dynamic analyses of machine tool structure are performed by commercial finite element package. The optimization process is controlled and solved by using the functions build in commercial mathematical software. The optimal design gives $13.3 \%$ reduction in volume, while $y$ displacement and 2nd natural frequency were confined to given scopes. The following specific conclusions can be drawn

1. The surface response method used as metamodel is successful for modeling structural static and dynamic analysis results for structural optimization.

2. For limited range of design variables the second order surface response model with Box-Behnken design can give good approximation compared with higher order response surface model.

\section{ACKNOWLEDGEMENTS}

This study was supported by the research project (NSC 102-2218-E-003-001-MY2) of Ministry of Science and Technology of R.O.C. The authors would like to thank the team members of other sub-project for their assistances.

\section{REFERENCES}

[1] Cheng, K., Machining Dynamics: Fundamentals, Applications and Practices, Springer-Verlag: London, pp. 1-2, 2009.

[2] Liang, Y., Chen, W., Sun, Y., Luo, X., Lu, L. \& Liu, H., A mechanical structure-based design method and its implementation on a fly-cutting machine tool design, International Journal of Advanced Manufacturing Technology, 70, pp. 1915-1921. 2014.

[3] Zaeh, M.F. \& Hennauer, M., Prediction of the dynamic behaviour of machine tools during the design process using mechatronic simulation models based on finite element analysis, Production Engineering Research and Development, 5, pp. 315-320, 2011.

[4] Kono, D., Lorenzer, T., Weikert, S. \& Wegener, K., Evaluation of modelling approaches for machine tool design, Precision Engineering, 34, pp. 399-407, 2010.

[5] Forrester, A.I.J. \& Kean, A.J., Recent advances in surrogate-based optimization, Progress in Aerospace Sciences, 45, pp. 50-79, 2009.

[6] Simpson, T.W., Peplinski, J.D., Koch, P.N. \& Allen, J.K., Metamodels for computer-based engineering design: survey and recommendations, Engineering with Computers, 17, pp. 129-150, 2001.

[7] Reisenthel, P.H., \& Lesieutre, D.J., Statistical Benchmarking of Surrogate-Based and other optimization methods constrained by fixed computational budget, Proc. of the 51st AIAA/ASME/ASCE/AHS/ASC Structures, Structural Dynamics, and Materials Conference, Curran Associate: New York, pp. 7768-7783, 2010.

[8] Chakraborty, S. \& Sen, A., Adaptive response surface based efficient Finite Element Model Updating, Finite Elements in Analysis and Design, 80, pp. 33-40, 2014.

[9] Bezerra, M.A., Santelli, R.E., Oliveira, E.P., Villar, L.S. \& Escaleira, L., Response surface methodology (RSM) as a tool for optimization in analytical chemistry, Talanta, 76, pp. 965-977, 2008.

[10] Khuri, A.I. \& Mukhopadhyay, S., Response surface methodology, Wiley Interdisciplinary Reviews: Computational Statistics, 2(2), pp. 128-149, 2010.

[11] Montgomery, D.C., Design and Analysis of Experiments, Wiley: New York, pp. 181-13, 2001.

[12] Ferreira, S.L.C., Bruns R.E., Ferreira, H.S., Matos, G.D., David, J.M., Brand ao, G.C., da Silva, E.G.P., Portugal, L.A., dos Reis, P.S., Souza, A.S. \& dos Santos, W.N.L., Box-Behnken design: an alternative for the optimization of analytical methods, Analytica Chimica Acta, 597, pp. 179-186, 2007.

[13] Rao, S.S., Engineering Optimization: Theory and Practice, John Wiley \& Sons: New York, pp. 436-442, 1996.

[14] Bhatti, M.A., Practical Optimization Method with Mathematica Application, Springer-Verlag: New York, pp. 315-436, 2000. 